Davidson, F. F. (1959). J. gen. Microbiol. 20, 605-611

\title{
Effects of Extracts of Blue-Green Algae on Pigment Production by Serratia marcescens
}

\author{
By F. F. DAVIDSON \\ Department of Biology, Baylor University, Waco, Texas, U.S.A.
}

SUMMARY: Two extract preparations from each of twelve species of blue-green algae were tested for possible anti-pigmentation activities when applied to unpigmented cultures of Serratia marcescens. Extracts from eight of these species inhibited pigment formation, two of them completely. The two extraction methods gave similar results and there appears to be no difference in the effects produced by extracts from pure and impure algal cultures. Living or preserved samples of the algae containing the anti-pigmentation factor (APF) were also toxic to mice when whole or homogenized organisms were injected intraperitoneally. Numerous tests showed that the bacterial associates of the algae did not enter into the production of the APF or the toxic substance. The most effective extract concentration was $0.2 \mathrm{ml}$. extract $/ \mathrm{ml}$. broth, and within the range of concentrations employed, the degree of pigment inhibition was inversely proportional to the extract concentration. The possibility of using the anti-pigmentation test to determine the presence of toxic substances in blue-green algae is suggested.

Although the toxic effects of certain blue-green algae on wild and domestic animals are well known, little information is available about the antibacterial activities of these organisms or their exudates. It has been reported that Microcystis aeruginosa Kütz. possesses some antibacterial properties against certain Gram-positive and Gram-negative bacteria (Lefevre, Jakob \& Nesbet, 1952; Wurtz, 1949), and that Oscillatoria splendida Grew, under certain conditions, secretes a volatile substance which kills bacteria and other microorganisms (Goryunova, 1955). Results obtained in this laboratory during the last three years confirm the belief that other Cyanophycean species, especially those which are toxic to higher animals, also possess antibacterial properties. During the course of this investigation on the effects of extracts of blue-green algae on certain forms of Enterobacteriaceae, the possible existence of an anti-pigmentation factor (APF) in certain of these extracts was indicated. Extracts which inhibited pigment formation by certain chromogenic bacteria did not affect their growth processes; and within the range of concentrations used the degree of pigment inhibition appeared to be inversely proportional to the concentration of the applied extract. The first indication of an antipigmentation activity was observed in cultures of Serratia marcescens Bizio. which had been treated with aqueous extracts from Microcystis aeruginosa Kütz. or from Nostoc rivulare Kütz. Further observations revealed that corresponding concentrations of extracts from certain other blue-green algae exhibited a similar but less pronounced inhibitory action. In view of these preliminary results, a survey was undertaken to determine the occurrence of the APF in a selected group of blue-green algae, including some of those which 
have been implicated in the death of higher animals, and to determine the concentrations of each extract required for the inhibition of pigment formation by $\boldsymbol{S}$. marcescens Bizio.

It has been well established that the biosynthesis of prodigiosin, the tripyrrylmethane pigment of Serratia marcescens Bizio (Hubbard \& Rimington, 1950 ) is influenced by such factors as radiation, temperature, $\mathrm{pH}$ value of the growth medium, age of the culture, chlorophyll, numerous organic substances, and by certain antibiotics (Kreitlow, 1942; Novelli, 1953; Weinberg, 1951; Weil, 1952; Bunting, 1950; Crichton \& Lazarus, 1948; Williams, Green \& Rappoport, 1956). In the present study, the factors temperature, light, $\mathrm{pH}$ value and age of cultures were controlled. Weil (1952) demonstrated that Terramycin and Aureomycin are capable of inhibiting the formation of prodigiosin by $S$. marcescens. Although the active principle considered in the present report has not been identified, preliminary studies indicate that its pigment-inhibition properties resemble those of Terramycin and Aureomycin.

\section{METHODS}

Blue-green algae tested. Nine unialgal, bacteria-contaminated cultures were obtained from the Indiana University stock culture collection for use in this study. The strain number is given in parentheses after each species: Tolypothrix distorta var. symplocides Hansg. (B 424); Anabaena catenula (Kütz. Born. et Flah. (B375)); A. variabilis Kütz. (B377); Nostoc ellipsosporum (Desmaz.) Rabenh. (B383); N. calcicola Breb. (B382); N. punctiforme (Kütz). Hariot. (B384); Calothrix membranacea Schmidle (B 379); Oscillatoria tenuis Ag. (B 428); Lyngbya sp. (487). Pure cultures of Microcystis aeruginosa Kütz. were obtained from Dr G. C. Gerloff (University of Wisconsin) and O. formosa Bory (strain LB390) from the Indiana University stock culture collection. Samples of $\boldsymbol{N}$. rivulare Kütz. and $\boldsymbol{M}$. aeruginosa Kütz. were collected locally and the identifications were verified by Dr F. Drouet (Cryptogamic Herbarium, Chicago Natural History Museum). These two species were established in unialgal cultures but were not bacteria-free.

Jelly-like masses of Nostoc rivulare Kütz. were transferred to the laboratory where they were spread into thin layers on plastic sheets. The material was fan-dried at $30^{\circ}$ for $24 \mathrm{hr}$., powdered in a Waring blendor and stored in sealed containers. The toxicity of the algae at different stages of preservation was tested by intraperitoneal injections in mice.

Algae grown in the laboratory were dried under reduced pressure at $60^{\circ}$ and were stored in separate containers.

Culturing the algae. In order to provide an adequate and reliable supply of algal material, cultures of the species employed were established in carboys or in Erlenmeyer flasks. The carboys were aerated with compressed air and the flasks by agitation on a mechanical rocking device. Constant illumination (500 ft.-c.) was provided by $40 \mathrm{~W}$. cool-white fluorescent tubes, and the room temperature was thermostatically controlled at $26-30^{\circ}$. Several growth media were tested. The most effective were: Gerloff, Fitzgerald \& Skoog (1952) 
modification of no. 10 medium of Chu (1942); Benecke medium (De, 1939); Burkholder (1955) medium containing $20 \mathrm{ml}$. soil extract (Pringsheim, 1949), $0 \cdot 2$ g. $\mathrm{KNO}_{3}, 0.002$ g. $\mathrm{K}_{2} \mathrm{HPO}_{4}, 0 \cdot 002 \mathrm{~g} . \mathrm{MgSO}_{4} \cdot 7 \mathrm{H}_{2} \mathrm{O}, 100 \mathrm{ml}$. distilled water. Stock cultures were maintained on Cyanophycean agar or soil extract agar (Starr, 1956) in a stock culture room provided with a constant temperature of $20-24^{\circ}$, light intensity of $50-75 \mathrm{ft}$.-c., and relative humidity of $50-60 \%$.

Preparation of extracts. Several techniques were tested in an effort to obtain extracts which contained the active APF principle. Of these an adsorption and elution technique was inferior to the other extraction procedures; attempts to elute completely APF which had been adsorbed on activated charcoal gave unsatisfactory results.

Thirteen organic solvents were tested in the preparation of crude extracts: acetone, chloroform, carbon tetrachloride, ethyl acetate, benzene, light petroleum (boiling range $\mathbf{3 5} \cdot \mathbf{r}-\mathbf{3 6} \cdot \mathbf{7}^{\circ}$ ), toluene, pentane, methanol pyridine, ethylene dichloride, methylethyl ketone, $n$-hexane, and ethanol. These solvents were used successively on the same sample of dried algae for selective extraction, and separately on different samples. In each case ethanol was found to be the most effective solvent for extracting APF. In the preparation of the extracts by this method, $\mathbf{5 0} \mathrm{g}$. preserved algae was ground in a ball mill and thoroughly mixed with three times its volume of purified sand. Ethanol $(500 \mathrm{ml}$.) was percolated through the mixture at room temperature and evaporated under reduced pressure at $60^{\circ}$. The residue was viscous and tacky and approached a brittle solid when thoroughly dried. This residue was agitated with sterile double-distilled water for $2 \mathrm{hr}$. and after the suspended particles had settled, the aqueous extract was removed and tested on nutrient broth and nutrient agar for the presence of bacteria.

The most satisfactory results were obtained by the use of distilled water as the solvent for the APF. A sample $(0.5 \mathrm{~g}$.) of algae was ground in a ball mill for $12 \mathrm{hr}$. Sterile distilled water $(100 \mathrm{ml}$.) was added and ball-milling continued for $1 \mathrm{hr}$. Microscopic examination of the suspension revealed that after the ball-milling the algal cells were thoroughly disintegrated. The mixture was centrifuged and the supernatant fluid removed for filtration. In order to provide adequate sterilization of the filtrate and to avoid the possible adsorption of APF by paper or porcelain filters, a sintered-glass bacterial filter was used. Samples of the aqueous filtrate were tested for sterility on nutrient agar and in nutrient broth. The nature and amount of APF in the algae are unknown. Hence, its concentration can be expressed only in reference to weight of plant material to the volume of solvent employed, i.e. $0.5 \mathrm{~g}$. dried algae/ $100 \mathrm{ml}$. distilled water. In case the APF was lost on storage in an aqueous solution, only fresh extracts were tested.

From each of the species of algae mentioned above two kinds of extract were prepared, i.e. by organic solvent and by distilled water extraction. The $\mathrm{pH}$ value of the prepared extracts was $7 \cdot 5-7 \cdot 7$.

Testing of extracts. The test organism used was Serratia marcescens, strain 261 (Indiana University stock culture collection). This strain was selected because of its ability to produce intense pigmentation in Difco nutrient broth, the 
medium used throughout this study. In nutrient broth, maximum growth and pigmentation occurred within $\mathbf{7 2} \mathrm{hr}$. when the cultures were incubated at $20-25^{\circ}$ in total darkness.

To three tubes each containing $48 \mathrm{mg}$. dehydrated nutrient broth, were added 5,4 or $3 \mathrm{ml}$. of distilled water. After the tubes were autoclaved at $121^{\circ}$ for $20 \mathrm{~min}$. and cooled, 1,2 and $3 \mathrm{ml}$. sterile aqueous filtrate respectively were added to the tubes, so that the nutrient broth concentration and the volume of medium in the tubes was the same throughout. The final concentration of extract in the three tubes was $\mathbf{0 . 2}, \mathbf{0 . 5}$ and $1 \mathrm{ml} / \mathrm{ml}$. medium. A similar tube of medium without extract was also prepared. Each of the four tubes was inoculated with a loopful of a $24 \mathrm{hr}$. culture of Serratia marcescens. Two uninoculated control tubes were also used, one containing medium only and the other only sterile aqueous filtrate plus water to $6 \mathrm{ml}$.

A second series of six tubes was prepared as above to test the anti-pigmentation activity of the aqueous extract. The final $\mathrm{pH}$ value of the experimental and control cultures remained at $7 \cdot 5-7 \cdot 7$. The twelve tubes in the two series were mechanically rotated for $72 \mathrm{hr}$. in a dark room at $26-30^{\circ}$.

Bacterial associates of each species of algae employed were isolated and tested for possible anti-pigmentation properties. Cultures $(48 \mathrm{hr}$.) of these bacteria were centrifuged for $1 \mathrm{hr}$., the deposit was removed, the organisms washed in two changes of normal saline and then suspended in $2 \mathrm{ml}$. normal saline. These bacterial suspensions were applied to cultures of Serratia marcescens in concentrations corresponding to those of the algal extracts. Control cultures were prepared as in the preceding tests. The tubes were mechanically rotated under environmental conditions identical with those used in the algal extract experiments.

Extraction of prodigiosin. For this procedure, Hubbard \& Rimington (1950) method was modified. Water lost from the culture through evaporation during the $72 \mathrm{hr}$. incubation period was restored. Acetone containing $2 \%(\mathrm{v} / \mathrm{v})$ of glacial acetic acid $(6 \mathrm{ml}$.) was mechanically shaken with the culture for 30-45 min. The prodigiosin was then extracted three times with light petroleum (b.p. 35.7-36.7 $7^{\circ}$ ), using $6 \mathrm{ml}$. for each extraction. The third extraction showed an optical density of 0 , indicating that all of the prodigiosin had been removed from the culture. The light petroleum extracts were pooled and the optical density was recorded. Readings were taken at wavelength $570 \mathrm{~m} \mu$, the maximum absorption of prodigiosin in these tests. The results are recorded in Table 1. The optical density readings of the acidic acetone cultures $(12 \mathrm{ml}$.) without prodigiosin are recorded in Table 2.

\section{RESULTS}

The effects of different concentrations of extracts of blue-green algae on the production of 1 rodigiosin by Serratia marcescens during an incubation period of $\mathbf{7 2} \mathrm{hr}$. are shown in Table 1. The data represent the optical density of light petroleum extracts of prodigiosin from untreated cultures and from algal extract-treated cultures of $\boldsymbol{S}$. marcescens. Prodigiosin extract from cultures of 
S. marcescens treated with aqueous extract or aqueous filtrate from Microcystis aeruginosa or from Nostoc rivulare at concentration $0.2 \mathrm{ml} . / \mathrm{ml}$. medium had an optical density of 0 , indicating the absence of pigment. Extract from untreated cultures of $S$. marcescens gave an optical density reading of 0.15. Both extracts from Oscillatoria formosa $(0 \cdot 2 \mathrm{ml} . / \mathrm{ml}$. medium) produced some inhibition of pigment formation, although not complete. Aqueous filtrates from N. ellipsosporum, N. calcicola, N. punctiforme, Calothrix membranacea and Anabaena variabilis produced partial inhibition. Aqueous extracts of $N$. calcicola and $N$. punctiforme also produced partial inhibition. Extracts from other species of blue-green algae tested produced no effect on cultures of $S$. marcescens.

In cultures of Serratia marcescens, in which complete or partial inhibition of pigment formation was produced APF remained effective for $96 \mathrm{hr}$. after which a gradual increase in pigmentation was observed. After incubation for 7 days there was little difference between the optical density of the experimental and control cultures. Tests on extracts from bacteria-contaminated cultures of algae gave the same results as extracts from bacteria-free cultures. Aqueous extracts or aqueous filtrate from bacteria isolated from the blue-green algae cultures exhibited no anti-pigmentation activities

Table 1. Effect of blue-green algae extracts on the production of prodigiosin by Serratia marcescens during an incubation period of $72 \mathrm{hr}$.

The data represent the optical density of light petroleum extracts of prodigiosin from algal extract-treated cultures and from untreated cultures of $S$. marcescens.

\begin{tabular}{|c|c|c|c|c|c|c|c|}
\hline \multirow[b]{2}{*}{ Source of extracts } & \multicolumn{3}{|c|}{$\begin{array}{l}\text { Aqueous extract } \\
\text { (ml./ml. medium) }\end{array}$} & \multicolumn{3}{|c|}{$\begin{array}{l}\text { Aqueous filtrate } \\
\text { (ml./ml. medium) }\end{array}$} & \multirow{2}{*}{$\begin{array}{l}\text { Untreated } \\
\text { cultures }\end{array}$} \\
\hline & 0.20 & $0 \cdot 50$ & $1 \cdot 00$ & $0 \cdot 20$ & $0 \cdot 50$ & $1 \cdot 00$ & \\
\hline Microcystis aeruginosa & $0 \cdot 00$ & $0 \cdot 03$ & $0 \cdot 04$ & $0 \cdot 00$ & $0 \cdot 03$ & $0 \cdot 05$ & $0 \cdot 15$ \\
\hline Oscillatoria formosa & 0.06 & $0 \cdot 07$ & 0.07 & $0 \cdot 05$ & $0 \cdot 09$ & $0 \cdot 10$ & $0 \cdot 15$ \\
\hline O. tenuis & $0 \cdot 15$ & $0 \cdot 16$ & $0 \cdot 16$ & $0 \cdot 15$ & $0 \cdot 15$ & $0 \cdot 16$ & $0 \cdot 16$ \\
\hline Nostoc ellipsosporum & $0 \cdot 15$ & $0 \cdot 16$ & $0 \cdot 15$ & 0.02 & $0 \cdot 04$ & $0 \cdot 13$ & $0 \cdot 15$ \\
\hline N. calcicola & $0 \cdot 14$ & $0 \cdot 09$ & $0 \cdot 15$ & 0.03 & $0 \cdot 08$ & $0 \cdot 14$ & $0 \cdot 16$ \\
\hline N. rivulare & 0.00 & 0.02 & 0.03 & $0 \cdot 00$ & $0 \cdot 02$ & $0 \cdot 03$ & $0 \cdot 15$ \\
\hline N. punctiforme & 0.06 & 0.08 & $\mathbf{0} \cdot 13$ & $0 \cdot 03$ & 0.06 & $0 \cdot 15$ & 0.15 \\
\hline Calothrix membranacea & $0 \cdot 15$ & $0 \cdot 15$ & $0 \cdot 16$ & 0.02 & $0 \cdot 04$ & $0 \cdot 15$ & 0.15 \\
\hline Anabaena variabilis & $0 \cdot 15$ & $0 \cdot 15$ & $0 \cdot 15$ & $0 \cdot 15$ & $0 \cdot 16$ & $0 \cdot 16$ & $0 \cdot 15$ \\
\hline A. catenula & $0 \cdot 16$ & $0 \cdot 16$ & $0 \cdot 15$ & $0 \cdot 15$ & $0 \cdot 15$ & $0 \cdot 16$ & $0 \cdot 16$ \\
\hline Tolypothrix distorta & $0 \cdot 15$ & $0 \cdot 15$ & $0 \cdot 16$ & $0 \cdot 15$ & $0 \cdot 16$ & $0 \cdot 15$ & $0 \cdot 15$ \\
\hline Lyngbya sp. & $0 \cdot 16$ & $0 \cdot 16$ & $0 \cdot 15$ & 0.15 & $0 \cdot 15$ & $0 \cdot 15$ & $0 \cdot 16$ \\
\hline
\end{tabular}

It was important to determine whether the differences in the amount of pigment produced were caused by differences in the amount of growth of the bacteria. The data in Table 2 represent the optical density of algal extracttreated cultures and the untreated cultures of Serratia marcescens after the prodigiosin had been extracted. The optical density of these cultures was $0.31( \pm 0.02)$. It is evident, therefore, that the differences were not caused by differences in bacterial growth.

The optical density of sterile extract $(0 \cdot 02)$ and of sterile medium $(0 \cdot 20)$ was unchanged during the $72 \mathrm{hr}$. incubation period. 
Table 2. Effect of extracts of blue-green algae on the growth of Serratia marcescens during an incubation period of $72 \mathrm{hr}$.

The data represent the optical density of algal extract-treated cultures and of untreated cultures of $S$. marcescens after the prodigiosin was extracted.

\begin{tabular}{|c|c|c|c|c|c|c|c|}
\hline \multirow[b]{2}{*}{ Source of extracts } & \multicolumn{3}{|c|}{$\begin{array}{l}\text { Aqueous extract } \\
\text { (ml./ml. medium) }\end{array}$} & \multicolumn{3}{|c|}{$\begin{array}{l}\text { Aqueous filtrate } \\
\text { (ml./ml. medium) }\end{array}$} & \multirow{2}{*}{$\begin{array}{l}\text { Untreated } \\
\text { cultures }\end{array}$} \\
\hline & $0 \cdot 20$ & 0.50 & $1 \cdot 00$ & $0 \cdot 20$ & 0.50 & $1 \cdot 00$ & \\
\hline Microcystis aeruginosa & $0 \cdot 31$ & $\mathbf{0} \cdot \mathbf{3 1}$ & $0 \cdot 30$ & $0 \cdot 28$ & $0 \cdot 28$ & 0.31 & $0 \cdot 31$ \\
\hline Oscillatoria formosa & $0 \cdot 31$ & $\mathbf{0} \cdot \mathbf{3 1}$ & $\mathbf{0 \cdot 3 0}$ & $0 \cdot 29$ & $0 \cdot 31$ & $0 \cdot 31$ & $0 \cdot 30$ \\
\hline O. tenuis & $0 \cdot 33$ & $0 \cdot 32$ & $\mathbf{0} \cdot 32$ & $\mathbf{0} \cdot \mathbf{3 1}$ & $\mathbf{0} \cdot \mathbf{3 1}$ & $\mathbf{0} \cdot \mathbf{3 1}$ & $\mathbf{0} \cdot 33$ \\
\hline Nostoc ellipsosporum & $0 \cdot 32$ & $0 \cdot 31$ & $\mathbf{0 \cdot 3 1}$ & $\mathbf{0} \cdot \mathbf{3 0}$ & $\mathbf{0} \cdot \mathbf{3 1}$ & $\mathbf{0} \cdot \mathbf{3 3}$ & $0 \cdot 31$ \\
\hline N. calcicola & $0 \cdot 33$ & 0.32 & $0 \cdot 31$ & $0 \cdot 32$ & $0 \cdot 31$ & $0 \cdot 31$ & $0 \cdot 32$ \\
\hline N. rivulare & $0 \cdot 32$ & $0 \cdot 31$ & $0 \cdot 31$ & $\mathbf{0 \cdot 3 1}$ & 0.31 & 0.33 & $0 \cdot 31$ \\
\hline N. punctiforme & $0 \cdot 32$ & $\mathbf{0} \cdot 32$ & $0 \cdot 32$ & $0 \cdot 33$ & $\mathbf{0} \cdot \mathbf{3 3}$ & $0 \cdot 32$ & $0 \cdot 31$ \\
\hline Calothrix membranacea & $0 \cdot 33$ & $\mathbf{0 \cdot 3 1}$ & $0 \cdot 33$ & $0 \cdot 31$ & $\mathbf{0} 31$ & $0-31$ & $0 \cdot 32$ \\
\hline Anabaena variabilis & $0 \cdot 31$ & 0.31 & $0 \cdot 31$ & $0 \cdot 32$ & $\mathbf{0} \cdot \mathbf{3 3}$ & $\mathbf{0 \cdot 3 1}$ & $0 \cdot 30$ \\
\hline A. catenula & $0 \cdot 30$ & $0 \cdot 29$ & $0 \cdot 32$ & $0 \cdot 31$ & $0 \cdot 31$ & $\mathbf{0 . 3 1}$ & $0 \cdot 30$ \\
\hline Tolypothrix distorta & $0 \cdot 31$ & 0.31 & 0.31 & $0 \cdot 32$ & $0 \cdot 30$ & 0.32 & $0 \cdot 31$ \\
\hline Lyngbya sp. & $0 \cdot 31$ & $0 \cdot 31$ & $0 \cdot 33$ & $0 \cdot 30$ & $0 \cdot 32$ & 0.31 & $0 \cdot 31$ \\
\hline
\end{tabular}

\section{DISCUSSION}

The importance of using bacteria-free unialgal cultures in such an investigation is well known to the author. Although the Cyanophycean species used in this study were unialgal, only two, Microcystis aeruginosa Kütz. and Oscillatoria formosa Bory, were bacteria-free. Confirmation of results from impure algal cultures awaits the establishment of pure cultures, a project now being conducted in this laboratory. However, since the results obtained from pure and impure cultures of $\boldsymbol{M}$. aeruginosa Kütz. or $\boldsymbol{O}$. formosa Bory were the same, there is reason to believe that APF was produced only by the algae.

Various workers have shown that aqueous suspensions of Microcystis aeruginosa increase in toxicity as the cell walls rupture, either by natural decay or by quick-freezing in the laboratory. In the present series of tests, the toxic effects of aqueous suspensions of $\boldsymbol{M}$. aeruginosa or Nostoc rivulare on mice and the anti-pigmentation activities of their extracts were increased when the organisms were disintegrated in a ball mill before their application. These results, and the fact that only those algae which were toxic to mice contained APF, indicate a close relationship between the poisonous material and the anti-pigmentation substance. These results suggest, therefore, the possibility of using the anti-pigmentation test as a rapid means of detecting minute quantities of toxic material in blue-green algae.

This investigation was supported by a research grant E-1429 (C2) from the National Institute of Allergy and Infectious Diseases of the National Institutes of Health, United States Public Health Service. I would like to thank Dr F. Drouet, Cryptogamic Herbarium, Chicago Natural History Museum, for identifying the algae collected locally, and Dr G. C. Gerloff, University of Wisconsin, for supplying the bacteria-free culture of Microcystis aeruginosa Kütz. 


\section{REFERENCES}

Bunting, M. I. (1950). The effect of surface-active agents on color variation in aging populations of Serratia marcescens. J. Bact. 59, 241.

Burkholder, P. R. (1955). Culture collection of algae, Department of Bacteriology, University of Georgia, Athens, Georgia. (Mimeographed.)

CHU, S. P. (1942). The influence of mineral composition of the medium on the growth of plankton algae. I. Methods and culture media. J. Ecol. 30, 284.

Crichton, P. V. \& Lazarus, A. S. (1948). The relationship between prodigiosin production and catalase activity. J. Bact. 56, 375.

DE, P. K. (1939). The role of blue-green algae in nitrogen fixation in rice fields. Proc. roy. Soc. Bot. 127, 121.

Gerloff, F. C., Fitzgerald, G. P. \& Skoog, F. (1952). The mineral nutrition of Microcystis aeruginosa. Amer. J. Bot. 39, 26.

Goryunova, S. V. (1955). The occurrence of carnivorous blue-green algae. Microbiology, Moscow, 24, 271.

Hubbard, R. \& Rimington, C. (1950). The biosynthesis of prodigiosin, the tripyrrylmethene pigment from Bacillus prodigiosus (Serratia marcescens). Biochem. J. 46, 220.

Kreitlow, K. W. (1942). Some effects of visible radiation on pigmentation of Serratia marcescens. J. Bact. 42, 127.

Lefevre, M. H., JAKob, J. \& Nesbet, M. (1952). Auto- et heteroantagonisme chez algues d'eau douce. Ann. Sta. cent. Hydrobiol. appl. 4, 5.

Novelu, A. (1953). The influence of ultraviolet light and chlorophyll on the production of pigment by Bacterium prodigiosum (Serratia marcescens). J. Bact. 65,479 .

Pringsheim, E. G. (1949). Pure Cultures of Algae. Cambridge University Press.

Starr, R. C. (1956). Culture collection of algae at Indiana University. Lloydia, 19, 129.

WeIL, A. J. (1952). Inhibition of pigment formation of Serratia marcescens by chloramphenicol, aureomycin and terramycin. Proc. Soc. exp. Biol., N.Y. 79, 539.

Weinberg, E. D. (1951). The influence of antibiotics and amino acids on the production of pigment by Serratia. J. Bact. 62, 785.

Williams, R. P., Green, J. A. \& Rappoport, D. A. (1956). Studies on pigmentation of Serratia marcescens. I. Spectral and paper chromatographic properties of prodigiosin. J. Bact. 71, 115.

Wurtz, A. (1949). Propriétés particulières d'une fleur d'eau de Cyanophycée: Microcystis aeruginosa Kütz. Bull. Soc. bot. Fr. 96, 50.

(Received 28 November 1958) 